\title{
Potencia de la novela utópica, de Piglia a Walsh
}

\author{
Juan Pablo Luppi \\ Instituto de Literatura Hispanoamericana, Facultad de Filosofía y Letras, \\ Universidad de Buenos Aires / CONICET, Argentina
}

Recibido: 14/4/2018. Aprobado: 6/6/2018.

\begin{abstract}
Resumen
Anfibio entre crítica y ficción, el amplio campo de operaciones de lectura de Ricardo Piglia puede sesgarse en torno a la apreciación que ha realizado del proyecto de Rodolfo Walsh. Como muestra su trabajo novelístico, ensayístico, editorial y docente, especialmente en las décadas de 1990 y 2000 (pero también a principios de los años 70), la intervención de Piglia es decisiva para visibilizar la peligrosidad vigente de la escritura de Walsh y, a la vez, esa valoración hermenéutica repercute en su singular producción de hipótesis sobre la literatura hispanoamericana en el entre-siglos. El artículo indaga en qué medida las relaciones mutuas de lectura/escritura operan sobre el reparto dicotómico entre literatura y sociedad, que fue problematizado en la cultura argentina por los años de formación de Piglia (1957-1967, según el primer volumen de Los diarios de Emilio Renzi) y reformulado en el cambio de siglo con desplazamientos que, desde Piglia hacia Walsh, accionan la proyección de una novela con potencia ofensiva frente al consenso cultural del capitalismo tardío.
\end{abstract}

\section{Power of the utopian novel, from Piglia to Walsh}

\begin{abstract}
Amphibian between criticism and fiction, Ricardo Piglia's wide range of reading operations can be biased around his appreciation of Rodolfo Walsh's project. As his novelistic, essay, editorial and teaching work shows especially in the 1990 s and 2000 s (but also in the early 70), Piglia's intervention is decisive in order to make visible the current dangerousness of Walsh's writing, and at the same time that hermeneutic evaluation has repercussions on his singular production of hypotheses about Hispanic American literature in between-centuries. The article explores the extent to which the reading/writing mutual relations operate on the dichotomy between literature and society; this distribution was made problematic in the Argentine culture by the years of Piglia's formation (1957-1967 according to the first volume of Los diarios de Emilio
\end{abstract}

Palabras clave

Desplazamiento Ficción/Realidad Lectura de escritor Peligrosidad

\section{Keywords}

Displacement Fiction/Reality Writer's Reading Riskiness 
Renzi) and has been reformulated at the turn of the century with displacements that, from Piglia to Walsh, trigger the projection of a novel with offensive power against the cultural consensus of late capitalism.

\section{Uno}

El dato evidente de que Ricardo Piglia ha dedicado contundentes análisis críticos a la obra de Rodolfo Walsh puede sesgarse para indagar las intensas relaciones de lectura/escritura que la obra anfibia entre crítica y ficción, desarrollada por Piglia desde la década de 1960, entabla con el proyecto cercano y disímil de Walsh, abierto hacia 1950 y no cerrado por el asesinato estatal del escritor en 1977. Como muestra su trabajo novelístico, ensayístico, editorial y docente especialmente en las décadas de 1990 y 2000 (pero también a principios de los 70), la lectura de Piglia es decisiva para visibilizar la potencia abierta de la escritura fragmentaria y peligrosa de Walsh y, a la vez, esa valoración hermenéutica repercute en su singular producción de hipótesis sobre la literatura hispanoamericana en el entre-siglos. Buscaré en qué medida tales relaciones mutuas de lectura/escritura operan sobre el reparto dicotómico entre literatura y sociedad, problematizado en la cultura argentina por los años de formación de Piglia (1957-1967 según el primer volumen de Los diarios de Emilio Renzi) que, traspuestos a la trayectoria de Walsh, conectan el libro que parecía novela pero no era ficción y le cambió la vida (Operación masacre) con el libro de cuentos que los reseñadores sancionaron como promesa incumplida de una novela (Un kilo de oro). En el futuro de ese orden dispuesto sobre la conexión conflictiva entre arte y política, intentaré localizar las tensiones que, desde Piglia hacia Walsh, accionan la proyección de una novela con potencia ofensiva frente a las condiciones del presente.

Como la de otros autores argentinos que han sido objeto de su interés recurrente (Sarmiento, Macedonio, Arlt, Borges, Puig, Saer), la lectura que aporta Piglia al proyecto de Walsh ha tenido fuerte pregnancia en el campo literario hispanoamericano hasta el presente. Para tal verificación acaso no hace falta la visibilidad social de una de sus últimas operaciones sobre Walsh (la necesaria edición de Cuentos completos en 2013) ni la probada influencia que sus seminarios universitarios detentan en el campo académico y cultural. Publicado por Ediciones de la Flor en junio de 2013, el primer libro segmenta la producción cuentística resintiendo el peso de la noficción, al excluir cierta zona ficcional e incluir textos autobiográficos-testimonialesensayísticos: además de la entrevista de Piglia en 1970 y otra de Rosalba Campra en 1973, incorpora una carta privada de Walsh a Donald Yates en 1964 donde reflexiona sobre el oficio narrativo (y recomienda al investigador norteamericano traducir a Macedonio), pero excluye seis ficciones breves por considerarlas "simples ejercicios circunstanciales o irónicas pruebas de su inicial fervor borgeano", según la "Nota a esta edición" firmada "RP" (Walsh, 2013: 525). Significativamente, este criterio de selección mengua la sombra de Borges sobre la formación de Walsh, como ocurre en la ficción de diario de los años de formación de Piglia. Publicado por Eterna Cadencia a comienzos de 2016, Las tres vanguardias. Saer, Puig, Walsh reúne las once clases del seminario dictado por Piglia en 1990 en la UBA, el primero de varios que impregnarían los modos de leer de investigadores, docentes, narradores del ámbito hispanoamericano contemporáneo. Según la hipótesis inicial, durante la década del '6o se cierra la constitución de las grandes poéticas argentinas de la novela (Macedonio, Arlt, Marechal, Borges, Cortázar), con respecto a las cuales entablan continuidades y cortes las tres vanguardias. La valoración de Walsh se sostiene en el pasaje "de la forma breve a la no ficción" y en la contundente ubicación del autor en la "tradición antinovelística" ("que plantea que para pasar de la literatura a la realidad hay que abandonar la ficción"): destaca la experimentación procedimental 
de algunos cuentos ("Cartas", "Fotos", "Nota al pie") y revalúa Operación masacre en el contexto de la vanguardia histórica (el surrealismo y la vanguardia soviética de los 20, desde la lectura de Benjamin) (cf. Piglia, 2016: 13-14, 158-207).

Por debajo de esas dos intervenciones fuertes, el aporte de sentidos de Piglia sobre Walsh se extiende en una serie de interpretaciones críticas dispuestas entre lo oral y lo impreso en diversas formas y soportes, no siempre explícitamente dedicadas a Walsh. Uno al comienzo y otro hacia el final de la serie, dos textos pueden sintetizar la proyección de la poética de Walsh realizada por Piglia durante cuatro décadas, con una intensidad problemática abierta más allá de la visibilidad editorial reciente. La entrevista de 1970 publicada en 1973 por Siglo XXI como preliminar de Un oscuro día de justicia (libro formado por ese cuento y la entrevista), reeditada con ampliaciones en la revista porteña Crisis a fines de 1987, acaso sea la intervención más famosa de Piglia lector de Walsh, además de formar parte material y significativa de la obra de este. Tres décadas después aparece la sistematización acaso más sólida de Piglia sobre Walsh luego del seminario del 90 (no facturado editorialmente hasta 2016): una conferencia dictada en La Habana en 2000, publicada a principios de 2001 en la revista Casa de las Américas y, a fines de ese año, por el Fondo de Cultura Económica junto con la conferencia de León Rozitchner en el mismo encuentro.

Como toda su obra crítica, tramada en los bordes productivos del ensayo con la autobiografía y la ficción, generando formas que renuevan el campo académico sin cerrarse a sus métodos y jergas, estas dos intervenciones priorizan la cuestión de cómo se lee, enfocada en ese punto ciego de la recepción canónica que, reduciendo la complejidad de Walsh a la resolución de tensiones entre política y literatura en beneficio de la primera, descuida la pregunta política sobre la ficción que Piglia no ha dejado de formular: cómo devolver a la novela su potencia ofensiva frente al consenso cultural del capitalismo tardío. En el fragmentario desarrollo de esa preocupación de escritor-crítico o de narrador-ensayista, Piglia aporta legibilidad a la eficacia con que el proyecto Walsh formuló la misma pregunta en el momento de violenta emergencia del orden neoliberal. Para resignificar esa intervención que recortaré en los dos textos mencionados, conviene disponer algunos aspectos de la reflexión novelística de Piglia, entre su acabada realización (Blanco nocturno, novela policial de 2010 coprotagonizada por Renzi) y su proyección bajo el artificio del diario iniciático de Renzi (Años de formación, editado en 2015).

\section{Dos}

Mediante el desplazamiento y el anacronismo, la lectura de escritor visibiliza el proyecto de novela que Walsh dejó abierto, cuyos fragmentos resuenan en la novela realizada por Piglia. Los nexos críticos establecidos con la tradición del siglo XIX confirman la potencialidad de la novela para desmontar operaciones de escritura en las que se juegan la política y la lectura. Como destaca Adriana Rodríguez Pérsico (2015: 278-281) al explorar el diseño de una política del anacronismo en la poética de Piglia, mediante un trabajo de edición que introduce la distancia en la mirada y el montaje polifónico de tradiciones, Blanco nocturno "narra una historia policial casi perfecta excepto por el desenlace irresuelto", que potencia la novela con un impulso utópico que la instala "en el lugar de lo que no ha llegado a ser". Esa atopía permite visibilizar la novela documental y geológica que Walsh lanza al futuro, sobre la que planea la entrevista del 70.

Blanco nocturno pone en acción a un detective que ubica su linaje en la ficción walshiana, evitando la reducción de lo walshiano a la trayectoria vital que, por la acción periodística y por el modo de morir, ha convertido al autor en personaje (arriesgado 
detective digno de la serie negra, ícono del intelectual comprometido víctima del terrorismo estatal). Como retomaremos al final, será un personaje creado por Walsh (Laurenzi, comisario retirado que protagoniza siete cuentos desperdigados entre 1956 y 1964) quien inserte la incidencia del precursor en la ficción de Piglia -lo cual no impide que también se reescriba la marca del autor como personaje que signa lo walshiano-. Si el comisario Croce se convierte en otro tras la represión del levantamiento de junio de 1956 -"cuando supo que la rebelión había fracasado anduvo como muerto por los campos hablando solo y sin dormir y cuando lo encontraron ya era otro" (Piglia, 2010: 26)-, con eficacia aforística Walsh dirá que Operación masacre (libro surgido de la campaña periodística de investigación de un suceso obliterado en dicha represión) cambió su vida: "Haciéndola, comprendí que, además de mis perplejidades íntimas, existía un amenazante mundo exterior" (Walsh, 2007: 15). A diferencia de (y en diálogo con) esa irrupción de la (no)ficción en la propia vida, Piglia entromete su vida en la ficción mediante un personaje programáticamente doble del autor, llamado con su segundo nombre y su apellido materno (Emilio Renzi). Si la novela documental de Walsh tenía su potencia abierta con Operación masacre -cuya primera edición en 1957 se subtitula Un proceso que no ha sido clausurado-, por su parte Piglia indagó el género que imagina Renzi frente a la decepción final de Blanco nocturno: "La investigación no tiene fin, no puede terminar. Habría que inventar un nuevo género policial, la ficción paranoica" (Piglia, 2010: 284; itálicas en el original). Ambos modos de proyectar una ficción singular en la sociedad y la lengua argentina se cruzan en la necesidad de encarar la tensión entre paranoia-relato, vida-escritura, realidad-ficción, y a partir de allí transformar la inasible materia común (la historia, la verdad, moduladas en el habla, las voces) en una novela posible luego de las crisis de modernidad.

Trazada en anotaciones cotidianas, a la manera de los papeles personales de Walsh (2007) editados por Daniel Link en 1996, la búsqueda de una novela como ficción de verdad opuesta a las falsas ficciones estatales aparece con fuerza hacia el final del primer volumen de Los diarios de Emilio Renzi. En octubre del 66, Piglia le hace anotar a Renzi que "Mata-Hari 55" (uno de los cuentos más sólidos de La invasión) utiliza "microscópicamente el procedimiento de narración-verdad que pienso usar en la novela" (Piglia, 2015: 300). Mientras escribe sus primeros cuentos, la noticia de un robo bancario propicia el plan de una novela que pasará al acto tres décadas después, con Plata quemada en 1997 (así como la potencia manuscrita de los diarios traídos desde 1957 se actualizará como ficción de los diarios de Renzi en los últimos años de vida de Piglia: el desplazamiento ritma la progresión de la obra). La novela potencial aparece bocetada en el entrevero de realidad/ficción entre crónica policial y narración-verdad. En el origen de Renzi (contemporáneo de los cuentos de Laurenzi de Walsh) Piglia edita, en 2015, la incidencia de Walsh entre lo explícito y lo alusivo.

En enero del 67 reflexiona sobre el desafío de buscar "una prosa de media distancia que me permita salir de las formas breves": "Hay un riesgo pero también una gracia en la dispersión que me lleva de las notas fragmentarias de la novela a la busca de un tono en este cuaderno" (ibídem, 308). Leyendo como escritor, o mejor (como diría la sintaxis crítica que Piglia adapta del narrador conjetural de Borges) escribiendo como lector los diarios de una vida hecha de lectura/escritura, encuentra en Thomas De Quincey "la multiplicidad de puntos de vista y de textos ambiguos y posibles que se van reconstruyendo en ráfagas", cuya mezcla de técnicas de la crónica periodística y del policial conecta con In Cold Blood de Truman Capote: "Y eso es, exactamente, lo que imagino que quiero hacer en una novela". En junio de 1967 (a diez años de Operación masacre y poco antes de que aparezca Un kilo de oro), atendiendo al "debate actual que pronostica la desaparición de la novela, borrada por la voracidad popular de los mass media", el diario de Renzi considera que "la novela puede conservar la pasión por una experimentación libre" para ser "un reducto empobrecido de resistencia y de negatividad al estado de las cosas" (ibídem, 349). Alusiva en tales esbozos poéticos, 
la marca de Walsh se explicita en una decena de menciones, mayormente referidas al campo literario y editorial en que quiere insertarse Piglia en los sesenta. Cabe destacar una de enero de 1967 , porque Walsh aparece como primer lector profesional de Piglia y este aprovecha la instancia de evaluación editorial de su primer libro para proyectar la peligrosidad de su obra: "Jorge Álvarez parece entusiasmado con los cuentos. La semana próxima se va a constituir un «tribunal» presidido por Walsh para juzgarlos. Me gusta esa metáfora porque veladamente alude a la peligrosidad literaria que me gustaría que tuvieran mis escritos" (Piglia, 2015: 318; itálicas en el original).

\section{Tres}

Piglia realiza su política de lectura como reescritura del texto de otro, donde se confrontan distintas sensibilidades, no solo al vincular la conspiración arltiana con la ficción de Borges en una atmósfera macedoniana (como ha cristalizado la recepción), sino también cuando extiende esas fantasías a lo que supo ver como vanguardia entre sus contemporáneos Saer, Puig, Walsh, con quienes mantuvo diálogos modulados sobre la lectura de escritor. Walsh sería el interlocutor elegido para explorar esa preocupación central de Piglia en sus años de formación, según la edita en sus años de balance final: la conexión de las formas breves y la verdad social con una novela que pueda no ser borrada por la voracidad mediática. De eso trata buena parte de la entrevista que Piglia hace a Walsh en marzo de 1970, dándole pie para complejizar la recepción de sus cuentos más allá de las reseñas de Un kilo de oro en 1967 que demandaban a Walsh la producción de una novela. ${ }^{1}$ Piglia promueve la lectura autoral en torno a las tensiones entre documento y ficción, al iniciar la charla preguntando por la época de escritura de "Un oscuro día de justicia" en vinculación con "la serie de los Irlandeses", culminada por entonces con dicho cuento (aunque abierta en los papeles personales de Walsh, como se apreciará cuando se publiquen a mediados de los 90). La respuesta va de lo estético a lo político como de una esfera pasada a otra urgente; menciona la "realidad mixta" perceptible en ese "mundo de irlandeses" que "al mismo tiempo es en la Argentina", reconoce que en su producción "hay una evidente dicotomía" y destaca "cierta evolución en la serie" visible en la "nota política" del tercer cuento (la decepción del "pueblo" de alumnos ante la derrota del héroe venido de afuera para enfrentar al poder opresor). Matizando la determinación de la alegoría ("se me hizo consciente después"), la reflexión dialogada apunta al eje formal de la evolución narrativa, dado por la categoría de serie y la contigüidad entre cuentos y novela (Walsh, 1991: 8-11). En la disposición de la entrevista resuenan intereses fechados a fines de los 60 en los diarios de Renzi, abocados a la imaginación de una novela armada en la mezcla de crónica periodística y policial.

El intercambio procurado por Piglia supera limitaciones ideológicas de la recepción, que desde aquellos años centraba el valor de Walsh en la noficción popular y antiborgeana de Operación masacre (Ford, 1972; Rama, 1984). La entrevista verifica que no es un abandono de la literatura lo que Walsh realiza en la búsqueda de formas híbridas acaso incompatibles con la novela reclamada por la industria cultural, sino un cuestionamiento del concepto de novela y de la definición del escritor ante la politización radical de la cultura. Respondiendo al impulso novelístico que le confiere Piglia, Walsh proyecta la continuación de la serie: "En ese caso asumiría la forma de esas novelas hechas de cuentos que es una forma primitiva de hacer novela, pero bastante linda" (Walsh, 1991: 11). ${ }^{2}$ Como si anticipara su propia producción (que poco antes de su muerte re-fechará con los tres volúmenes de los diarios de Renzi, emanados de los cuadernos llevados por Piglia durante sesenta años), el entrevistador define "esa especie de novela" que "se va leyendo en textos discontinuos" dando protagonismo al lector, y pregunta a Walsh si ha pensado sobre esto. Antes de
1. La demanda es explícita desde los títulos de algunas reseñas: $E l$ mundo (s/firma), "Rodolfo Walsh. Le Reclaman una Novela”, 2ª sección, 8 de octubre de 1967, p. 43; A. C., "El prólogo de la novela", en Primera Plana, año V, n 248, 26 de septiembre al 2 de octubre de 1967, p. 77.

2. La corrección que hace Piglia de esa frase, cuando edita ampliada la entrevista en 1987, intentaría dar más espesor a la adjetivación de la forma novela, reemplazando el coloquial "bastante linda" por el interés que sigue teniendo el otro adjetivo que consideraría positivo (lo "primitivo" retomado), cayendo la conjunción adversativa ("pero"): “Sí, la forma de una novela hecha de cuentos, un modo primitivo de hacer novelas que siempre me interesó" (Walsh, 1987: 18; subrayado agregado). 
3. En un artículo de 2013 que retoma la conferencia de 2000 , Piglia elige el prólogo definitivo de Operación masacre (1969) y la "Carta a Vicky” (1976) para remarcar la propuesta de desplazamiento y distanciación de la experiencia: "Walsh hace ver de qué manera podemos mostrar lo que parece casi imposible de decir. (...). Salir del centro, dejar que el lenguaje hable también en el borde, en lo que se oye, en lo que llega de otro" (Piglia, 2013; itálicas en original). formular su argumentación a favor de "un nuevo tipo de arte más documental", Walsh expone la potencia proteica de disponibilidad ante la vida que lo define como escritor: "Sí, yo he pensado cosas muy contradictorias según mis estados de ánimo o, en fin, pasando por distintas etapas". Tras marcar distancia con Borges ("nadie le pide una novela"), se sostiene en la pregunta abierta, en el condicional modalizado como autosugerencia y el prefijo que indetermina la certeza: "habría que indagar, es decir no he terminado de convencerme ni de desconvencerme" (14).

Walsh y Piglia comparten la productividad crítica de la lectura de escritor, no como figura sacralizada por un saber, sino como sujeto que desde un lugar marginal define su oficio como el de escribir y leer en implicación mutua, que reconoce la pluralidad semántica del desplazamiento y la interrogación, con particular atención a las formas narrativas y el uso personal de la lengua común. Tales aspectos enfatiza Piglia en la conferencia del 2000, que ubica a Walsh en el centro de una tradición literaria hispanoamericana productiva para el porvenir. Con el programático título "Tres propuestas para el próximo milenio (y cinco dificultades)", focaliza en Walsh con el objeto de problematizar el futuro de la literatura y preguntarse qué tradición persistirá para quien ve el problema "desde un suburbio del mundo" (Piglia, 2001:11). Tras difundir en los primeros 90 su personal canon posborgeano, una década después refina la tensión entre arte y vida que ordenaba aquella postulación de tres nuevas vanguardias, y especifica en la forma el motivo de la permanencia de Walsh: el uso del lenguaje y la manera de frasear definirían un estilo concentrado, conformado por los matices del habla y la sintaxis oral. Más allá de Operación masacre el proyecto tiene vigencia por el devenir de una forma de escritura, un espacio nuevo de expresión para desarrollar dos búsquedas intensas, "descubrir la verdad que el Estado manipula, y, a la vez, escuchar el relato popular" (27-28): "Walsh produjo un estilo único, flexible e inimitable que circula por todos sus textos y por ese estilo lo recordamos" (42). Superando la escisión canónica pautada por la noficción, la valoración es más contundente que la del seminario del 90: como en la narrativa de Piglia, el pasaje de la literatura a la realidad puede hacerse sin abandonar la ficción.

Leído en términos de una poética política contemporánea al cambio de milenio, el estilo sería el movimiento hacia la alteridad enunciativa: al "poner a otro en el lugar de una enunciación personal", actualizando categorías formalistas y brechtianas como ostranenie o distanciamiento, Walsh amplía el reparto de lo decible y lo mostrable (36). ${ }^{3}$ Integrado a una serie hispanoamericana dinámica y contracanónica-Roberto Raschella, Rosa Chacel, Clarice Lispector, Juan Gelman, cuyos libros "parecen escritos en una lengua privada"- Walsh demuestra que para un escritor lo social está en el lenguaje. Esta revaloración excede la homogeneidad limitada a la determinación ideológica, al reconocer que el trabajo literario constituye en sí mismo una intervención política, decidida en la confrontación con los usos oficiales del lenguaje: la imposición de "una lengua técnica, demagógica, publicitaria", cuyo discurso dominante es el de la economía, establece "una norma lingüística que impide nombrar amplias zonas de la experiencia social y que deja fuera de la inteligibilidad la reconstrucción de la memoria colectiva". Contra la lengua mundial de la economía de mercado, la literatura tiene la opción (en el linaje Macedonio/Borges) de descontextualizar y "construir una contrarrealidad" (37-39). Pasadas dos décadas de la muerte de Walsh, su lectura se enriquece con la distancia ante determinaciones extraliterarias que marcaron su contexto (las que orientaban los atentos análisis de Rama y Ford, o las que presionaban como bajo continuo en el diálogo de 1970). Junto con otros proyectos hispanoamericanos fuertes en su marginalidad con respecto al Estado y al mercado, el de Walsh puede propiciar estos acentos de Piglia como constructor de tradiciones y modificador del canon, en polémica con agendas académicas y modas teóricas. Frente al dilema de la novela sobre el que Walsh en el 70 no terminaba de convencerse ni desconvencerse, Piglia será resolutivo y convincente. La valoración literaria de Walsh en el cambio de siglo quedará planteada en función de la figura de escritor crítico que por entonces ha consolidado Piglia. 


\section{Cuatro}

La marca de estilo y el uso del lenguaje son ejes por los que Piglia evita quedar encerrado en el dilema que pautaba su conversación con Walsh, según la percibe tres décadas después. En una página posliminar walshianamente titulada "Nota al pie", incluida en una edición de cuentos de Walsh prologada por Lafforgue en 2006, Piglia contextualiza las tensiones entre ficción y política que recorren la charla de 1970; destacando la inquietud teórica sobre los modos de leer, reitera la mención del procedimiento practicado en "Un oscuro día de justicia" y en "Esa mujer": el contexto aparece cifrado y actúa como clave interpretativa de la ficción. El énfasis en la acción lectora sofistica la confirmación de Walsh como escritor, más allá de las tensiones aglutinadas bajo el sintagma epocal del abandono de la literatura (que Piglia sostenía en el seminario del 90):

Walsh era demasiado consciente de la especificidad de la ficción como para intentar definir su eficacia de un modo directo y explícito. Pero a la vez su conciencia de las exigencias sociales y la urgencia de la intervención política lo hicieron poner rápidamente en cuestión la autonomía del mundo literario y la figura del hombre de letras (Piglia, 2006: 72).

La obra de Walsh extremaría esa cuestión clave en la historia de la cultura argentina, depositada en la palabra escritor (Piglia, 2006: 72-73). La eventual fuga del paradigma autonomista es reutilizada como prueba de valor intrínsecamente poético y no por eso menos político. En su apertura a la sensibilidad del otro, Piglia elude limitaciones en la recepción de Walsh que también han incidido en su propia obra, al pautarla como montaje de las tradiciones de Macedonio, Borges, Arlt entreveradas con la novela modernista (Joyce, Kafka, Mann) y la tradición narrativa norteamericana del siglo XX (de Faulkner-Hemingway a la serie negra). En su confrontación de Walsh con Piglia, Demaría (2001: 140-141) detecta que los papeles personales de Walsh "abren una zona intersticial" externa a las dicotomías burgués/revolucionario y ficción/ política, donde se presenta como problema el diálogo entre ambas prácticas. A diferencia del tono contundente que, en la entrevista de 1970, afirma la urgencia de dejar la ficción en beneficio de un arte documental, en el espacio privado de sus papeles Walsh se pregunta cómo incorporar a la ficción la experiencia política. Demaría propone una separación de Piglia con respecto a Walsh basada en la filiación autonomista con Macedonio que aquél postulaba en 1987, en "Ficción y política en la literatura argentina": el modo de unir política y ficción, de evitar enfrentarlas como prácticas irreductibles, constituye "la tranquera utópica de Macedonio" por donde cruzan Arlt, Marechal, Borges, "nuestra verdadera tradición" en la cual "la novela mantiene relaciones cifradas con las maquinaciones del poder", volviéndose una fuerza política que desenmascara al Estado como máquina de producir ficciones (Piglia, 1993a: 173-180). La perspectiva para conferir a Macedonio valores de precursor resuena en la lectura de "Esa mujer" que Piglia presenta en la conferencia del 2000, que corrige por anticipado la apreciación tajante de Demaría sobre su modo de "recoger solo en parte el legado de su entrevistado" de 1970 ("Piglia abandona a Walsh en el momento en que resuelve la dicotomía de la encrucijada" (140)). Como la misma crítica expone al enriquecer los problemas en torno a Walsh a partir de Ese hombre, y como ha insistido Piglia no solo en su lectura walshiana, si algo marca la relación entre literatura y política posterior a los 60 (desde cuya posición dialogaba Walsh con Piglia) es su falta de resolución, su apertura a colocaciones múltiples que exceden cualquier dicotomía. ${ }^{4}$

En la mixtura de cuento y entrevista, como procedimiento culminante en "Esa mujer", Piglia encuentra el modelo político de uso del lenguaje por el cual redefine la tradición, en consonancia con la tesis central para releer el XIX argentino a partir de Elmatadero
4. Al aceptar que la década del 60 sería "una marca de origen en su literatura”, como propone el entrevistador Carlos Dámaso Martínez en 1985, Piglia lo fundamenta en que "los 6o, como se los suele llamar, no son una época sino una posición. La circulación de los sentidos, el combate, la yuxtaposición, las variantes, cambiar de género y de tonos, manejar colocaciones múltiples". Oscar Masotta es para Piglia el ejemplo "clarísimo de ese espíritu”, y agrega: "Otro pueden ser los libros de Manuel Puig, también Rodolfo Walsh" (1993a: 144). 
5. En "Notas sobre Facundo", publicado en Punto de Vista (1980: 15-18), y “Echeverría y el lugar de la ficción”, en La Argentina en pedazos (1993: 8-10).

6. La encuesta entre escritores y críticos redundó en la selección editada por Sergio Olguín en 1999, Los mejores cuentos argentinos, publicado por Alfaguara.
7. “La expresión 'política de la literatura' implica que la literatura hace política en tanto literatura. Supone que no hay que preguntarse si los escritores deben hacer política o dedicarse en cambio a la pureza de su arte, sino que dicha pureza misma tiene que ver con la política" (Rancière, 2011: 15). y Facundo..$^{5}$ En la conferencia cubana, vincula el estado de la literatura argentina en el 2000 con la elección en una encuesta de "Esa mujer" como el mejor cuento de la literatura argentina, ${ }^{6}$ y con un consenso sobre el valor literario de Walsh que era "imposible imaginar hace un tiempo". Luego de destacar procedimientos narrativos agrupados por la sutileza y lo indirecto (elipsis, alusión, condensación, sobreentendido), ubica "Esa mujer" como inversión de El matadero en cuanto a la tensión entre los mundos letrado y popular, condensado este en la figura de Eva Perón, como secreto y enigma "pero también como un lugar de llegada": "cruzar la frontera ya no es encontrar un mundo de terror" como el de los matarifes donde se pierde el unitario. El mérito no canónico de Echeverría (disruptivo de la figura romántica de poeta pensador) estaría en su captación del habla popular ligada a la amenaza y el peligro, logrando un lenguaje muy vivo a partir del universo que quería denunciar. Hay una verdad en ese trabajo, no proclamada en la denuncia sino inserta en el uso del lenguaje, más allá de las decisiones políticas del escritor y los contenidos de la narración -como en la política de la literatura de Rancière. ${ }^{7}$ Si para un escritor lo social está en el lenguaje, la tradición futura que arma Piglia contrapone, a la despolitización de las lenguas técnicas, el trabajo microscópico de la literatura ejemplificado por el estilo mixto de Walsh.

Tal consideración permite desclasificar los estancos campos de actividad en que la cultura parcela la producción walshiana. En serie con el énfasis que la conferencia de 2000 reenvía a la entrevista de 1970, una contratapa de 1972 condensa el aporte de la intervención de Piglia en la revaloración poética de Walsh. La traducción hecha por Walsh de Viento rojo de Raymond Chandler es el doceavo título de la Serie Negra, dirigida por Piglia entre 1969 y 1977 en la editorial Tiempo Contemporáneo, cuyo propósito -contrapuesto al Séptimo Círculo donde Borges y Bioy Casares difundían centralmente policial inglés de enigma- era generar un espacio de lectura conectado con conflictos locales, realizando traducciones atentas a rasgos dialectales rioplatenses. La contratapa de Viento rojo editado por Piglia repite el párrafo sobre Chandler usado en otros títulos del autor publicados en la Serie, ubicándolo como exponente de que "el verdadero enigma que desentrañan las novelas de la serie negra es el de las relaciones capitalistas" -aspecto que, al marcar la distinción con el policial de enigma, la crítica por entonces repetía para valorizar Operación masacre como superación de Variaciones en rojo-. Lo que agrega esta contratapa con respecto a otras de Chandler en la colección es la mediación necesaria, central en la propuesta editorial, del otro autor escondido, el que ha acercado al idioma argentino la singular lengua norteamericana de Chandler: el "aspecto que, en oposición a las deplorables traducciones que en general han sufrido sus libros, la excelente versión de Rodolfo Walsh trasmite con fidelidad" consiste en "un estilo nervioso y ágil, de sutil construcción lírica y lúcida ironía". En el elogio de la transposición rioplatense de la prosa de Chandler asoma la eficacia poética que, tres décadas después, Piglia destacará en la fluidez sucinta de la escritura de Walsh. El hecho de encargarle la traducción indica el propósito de lucha contra formas cristalizadas de la lengua social (a las que contribuían las frecuentes "deplorables traducciones"). Editor crítico, Piglia inserta en el paratexto el foco sobre la lengua que, a comienzos de los 70, ya contiene la política de la literatura que en el 2000 sistematizará como propuesta futura centrada en Walsh.

\section{Cinco}

El uso privado de la tradición en acciones rigurosas de lectura/escritura renueva los modos de pensar y decir la violencia cultural argentina. El estilo de Walsh sería una puesta en acto de la política en la lengua, una novela potencial que ofrece a la lectura mucho más que un objeto impreso catalogable como ficción o noficción. Ese ímpetu encuentra la ocasión de un nuevo género en Operación masacre, orienta el montaje 
polifónico en "Esa mujer", "Nota al pie", "Cartas" y varios otros cuentos, y organiza micro emprendimientos periodísticos sustentados en la escucha de la comunidad de hablantes, como las crónicas de excursiones por zonas geográfica y económicamente limítrofes de Argentina en la segunda mitad de los 60, o impulsando otras prácticas y nuevas formas, como la agencia clandestina de noticias ANCLA en 1976. La hibridez y el desplazamiento que realiza el estilo de Walsh lanza la tradición hacia el futuro, y la obra de Piglia lo evidencia: abre posibilidades para el escritor argentino a comienzos del siglo XXI, laterales a Borges y Cortázar tanto como a Saer, Viñas o Arlt. Con respecto a Arlt, en tensión no con Borges sino con Cortázar, puede leerse un posicionamiento escrito en privado por Walsh, que también enfatiza la cuestión de las formas. En los papeles personales a fines de 1968, define la opción por "un Arlt y no un Cortázar", valorizando en el primero la fuerza, la capacidad dramática y "su decisión de enfrentar a los personajes"; sin embargo, advierte que "no me gustaría escribir una sola de sus frases", porque "ese odio rabioso" exige en el presente formas "mucho más cautelosas, inexpugnables, cerradas, que las de Arlt" (Walsh, 2007: 113-114, 119): las formas que Piglia destacará como tradición para el nuevo milenio.

Integrando a precursores también creados de otro modo por Walsh (Macedonio, Borges, Hemingway, Chandler) la novela de Piglia sería, entre múltiples opciones válidas, un modo desplazado de accionar la novela utópica de Walsh. Como anticipamos al comienzo, el comisario Croce, que deja de serlo y sigue resolviendo el caso desde un manicomio con ayuda de Renzi, explicita en Blanco nocturno el linaje de Laurenzi como justiciero argentino en declive, según se desprende de los siete casos de ese comisario si se leen como serie o novela hecha de cuentos. Como un lector que ha aceptado la suspensión de incredulidad, el narrador de Piglia amplifica el mundo ficcional leído en la serie de comisarios retirados como Leoni y Treviranus (creados respectivamente por Pérez Zelaschi y Borges), iniciada con el justiciero ambiguo de Walsh: "Laurenzi, su viejo amigo, lo habían pasado a retiro y vivía en el sur" (Piglia, 2010: 95-96). Además de varios guiños a Walsh en el mundo de personajes y en la sintaxis oral del narrador, el contrapunto final entre Croce y Renzi, al poner en cuestión el esperado restablecimiento del orden y la reconstrucción unívoca de una lógica del crimen, puede ser leído como otro homenaje a Walsh, cifrado en el espacio de la novela argentina del Bicentenario. En la escena del juicio que concluye Blanco nocturno, detrás de trascendentales abstractos como justicia y verdad "se jugaban la vida de un hombre, el futuro de la zona y una serie de cuestiones prácticas" (272); en el contrapunto epilogal con Renzi, el ex comisario de Piglia replica el tono vital del ex comisario de Walsh: "Pero la pifié -dijo después-, a nadie en el pueblo le convenía mi versión del crimen" (283). Ambas frases podrían condensar la moraleja evitada en esa novela invisible que arman los cuentos de Laurenzi, escritos por Walsh durante los años de formación de Piglia. ${ }^{8}$

La novela utópica, efectuada por Piglia en diálogo con la proyectada por Walsh, se despliega en soportes dispersos y formas híbridas (nota, diario, cuento, entrevista, conferencia, prólogo o epílogo) que arman relatos posibles de la interferencia mutua entre verdad y ficción, historia y sujetos, política y vida. No es una cuestión de influencia sino de activación de sentidos en la red de lectura reabierta en cada presente. Los linajes entreverados en la obra de Borges -la historia nacional fusionada a la memoria familiar y la biblioteca ilimitada de prevalencia inglesa- se vuelven, en la novela posible de Walsh (y en la más visible de Piglia), líneas contemporáneas del contexto de entresiglos, en un campo literario que después de Borges matiza y distancia la nostalgia épica y la norma cosmopolita, en beneficio de particulares proyectos que interrogan la ambigüedad de lo novelesco y reformulan la tradición con incisiones poéticas y políticas. La combinación de lo social con lo particular, lo histórico con lo doméstico, daría un sesgo necesario para superar el reparto entre literatura y política que afectó los años de formación de Piglia. Además, las varias formulaciones del doble linaje muestran estrategias
8. Realicé un análisis de la probable novela Laurenzi en el capítulo "Declive del justiciero" de Una novela invisible. La poética política de Rodolfo Walsh (Villa María, Eduvim, 2016: 157-179). 
9. Al desplazamiento de género y soporte (y público) se agrega el anacronismo, aplicado a Borges como "el mejor escritor argentino del siglo XIX" en la payada intelectual entre Renzi y Marconi en Respiración artificial (1994: 126129), que a su vez conecta con otra intervención mencionada, decisiva para releer el siglo XIX, publicada en Punto de Vista un año después de la dedicada a Borges: "Ideología y ficción en Borges" y "Notas sobre Facundo" sientan las bases de la operación de recontextualización en torno a los dos grandes escritores argentinos del XIX (Sarmiento y Borges) según la hipótesis de Renzi en la novela de 1980 eficaces de concomitancia entre estilo crítico y soporte editorial. Auténtico hit de la transmisión contemporánea de la literatura argentina, tiene su primera versión en "Ideología y ficción en Borges", aparecido en marzo de 1979 en el quinto número de Punto de Vista, y cinco años después su transposición divulgadora en "Borges y los dos linajes", publicado a mediados de los 80 en la sección de la revista Fierro titulada "La Argentina en pedazos" y luego en el libro homónimo (Piglia, 1993: 102-104).9 Para 1984 Piglia ha dejado el grupo de Punto de Vista en beneficio de otro tipo de intervención mediática, como la que inicia en Fierro con esa sección que será a la vez masiva y académica; en el recorrido no solo reformula el canon literario nacional sino que reversiona sus lecturas con reescrituras y reediciones en nuevos soportes.

Madura reversión de la obsesión constante por las operaciones de lectura (gozosamente diseminadas entre Borges, Mansilla, Kafka, Tolstoi, Joyce, Guevara...), mapa privado y arbitrario de "algunos modos de leer que están en mi recuerdo", El último lector reubica la consabida segmentación (literatura y política) en la tensión clásica de la novela moderna, entre ficción y realidad. La vida concebida como una novela en Anna Karenina, la entrada en la ilusión para confrontar desde allí la realidad, constituye la intensidad del mundo novelístico, "la novela misma, la forma del género" (Piglia, 2005: 145, 190). Reevaluando dos páginas de Cortázar ("Continuidad de los parques") Piglia sintetiza el cruce que ejecuta la ficción hacia lo real, como una operación interna al acto de leer, donde la construcción de un mundo paralelo irrumpe como realidad. Como en Años de formación, en El último lector la marca de Walsh merodea el orden del libro pero nunca (casi nunca en el primer caso) se explicita; uno de los énfasis donde asoma esa marca desarticula las prevenciones autonomistas y define la resolución de la tensión decisiva que Walsh lanzó a la posteridad: "El contraste entre ficción y realidad se ha invertido. La realidad misma es incierta y la novela dice la verdad (no toda la verdad)" (144, 148, 151-152). Disonante en la esfera pública, la lectura ficcional pone en tensión las verdades impuestas por el Estado y el mercado: interviene peligrosamente en el funcionamiento de lo real.

En el último tomo de Los diarios de Emilio Renzi (publicado póstumo en 2017), mientras escribe Respiración artificial y relee El Capital reconfirmando ideas sobre el concepto de "trabajo improductivo", en febrero de 1979 Piglia le hace anotar a Renzi esa inversión del diálogo entre ficción y realidad: "Por ese lado de puede analizar el lugar social de la literatura, es decir, el lugar de la literatura en lo social (que me interesa más que a la inversa, o sea, el lugar de la sociedad en la literatura)" (88). El movimiento de la literatura hacia lo real que Piglia fue recortando y ampliando en fragmentos entreverados de crítica y ficción, junto con la exploración de cruces entre lo particular y lo histórico, conforman una acción lectora que sostiene la performatividad de la novela en las sociedades hispanoamericanas a comienzos del XXI. Como la utopía leída por Rodríguez Pérsico en Blanco nocturno, Walsh leído por Piglia provoca una novela inacabable, dispuesta en el lugar de lo que no ha llegado a ser. En la poética del desplazamiento y la peligrosidad, accionada en las formas de leer escribiendo de Piglia, resuena la potencia utópica que Walsh ofrece a la incierta realidad contemporánea. 


\section{Bibliografía}

»Chandler, R. (1972). Viento rojo (trad. Walsh, R.). Buenos Aires: Tiempo Contemporáneo.

"Demaría, L. (2001). "Rodolfo Walsh, Ricardo Piglia, la tranquera de Macedonio y el difícil oficio de escribir". En Revista Iberoamericana, vol. LXVII, núm. 194195, enero-junio, pp. 135-144.

" Ford, A. (1972 [1969]). "Walsh: la reconstrucción de los hechos". En Lafforgue, J. (comp.). Nueva novela latinoamericana II. La narrativa argentina actual. Buenos Aires: Paidós.

» Piglia, R. (1979). “Ideología y ficción en Borges”. En Punto de Vista, año II, núm. 5, marzo, pp. 3-6.

»Piglia, R. (1994 [1980]). Respiración artificial. Buenos Aires: Seix Barral.

»Piglia, R. (1980). “Notas sobre Facundo”. En Punto de Vista, año III, núm. 8, pp. 15-18.

» Piglia, R. (1993). La Argentina en pedazos. Buenos Aires: La Urraca.

»Piglia, R. (1993a). Crítica y ficción. Buenos Aires: Fausto-Siglo veinte-UNL.

»Piglia, R. (2001). Tres propuestas para el próximo milenio (y cinco dificultades). Buenos Aires: Fondo de Cultura Económica.

»Piglia, R. (2005). El último lector. Barcelona: Anagrama.

»Piglia, R. (2006). “Nota al pie”. En Walsh, R. Un oscuro día de justicia. Zugzwang. Buenos Aires: Ediciones de la Flor.

»Piglia, R. (2010). Blanco nocturno. Barcelona: Anagrama.

" Piglia, R. (2013). “Una propuesta para el próximo milenio". En Cuadernos LIRICO, núm. 9. Puesto en línea el 1 septiembre 2013, consultado el 14 marzo 2017. Disponible en <http://lirico.revues.org/1101; DOI : 10.400o/lirico.1101>.

»Piglia, R. (2015). Los diarios de Emilio Renzi. Años de formación. Barcelona: Anagrama.

»Piglia, R. (2016). Las tres vanguardias. Saer, Puig, Walsh. Buenos Aires: Eterna Cadencia.

»Piglia, R. (2017). Los diarios de Emilio Renzi. Un día en la vida. Barcelona: Anagrama.

»Rama, Á. (1984) [1974]. "Rodolfo Walsh: La narrativa en el conflicto de las culturas”. En Literatura y clase social. Buenos Aires: Folios.

»Rancière, J. (2011). Política de la literatura. Buenos Aires: Libros del Zorzal.

»Rodríguez Pérsico, A. (2015). "Las huellas del género. Sobre Blanco nocturno de Ricardo Piglia". En La Biblioteca, núm. 15: El arte de narrar. Variaciones sobre Ricardo Piglia, primavera, pp. 278-287.

»Walsh, R. (1991 [1973]). “Hoy es imposible en la Argentina hacer literatura desvinculada de la política" (entrevista de Piglia, 1970). En Walsh, R. Un oscuro día de justicia, Buenos Aires, Siglo XXI, pp. 5-24. Versión ampliada: Walsh, R. (1987). "He sido traído y llevado por los tiempos”. En Crisis, núm. 55, noviembre, pp. 16-21.

»Walsh, R. (2007 [1996]). Ese hombre y otros papeles personales (ed. Link, D.). Buenos Aires: Ediciones de la Flor.

"Walsh, R. (2013). Cuentos completos (ed. y pról. Piglia, R.). Buenos Aires: Ediciones de la Flor. 
